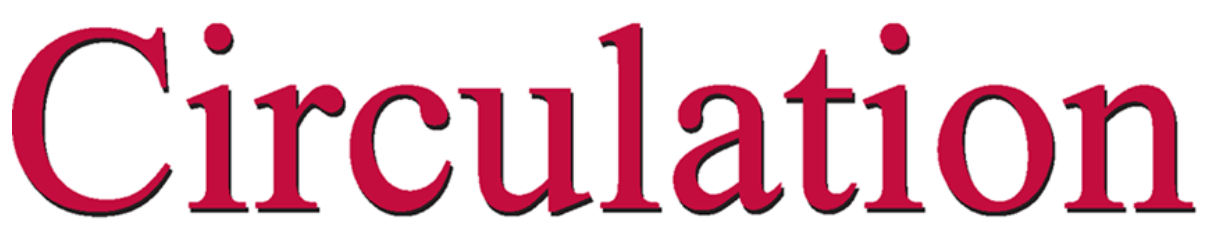

JOURNAL OF THE AMERICAN HEART ASSOCIATION
American Heart Association

Learn and Live

\title{
Lack of Neointimal Proliferation After Implantation of Sirolimus-Coated Stents in Human Coronary Arteries : A Quantitative Coronary Angiography and Three-Dimensional Intravascular Ultrasound Study
}

J. Eduardo Sousa, Marco A. Costa, Alexandre Abizaid, Andrea S. Abizaid, Fausto Feres, Ibraim M. F. Pinto, Ana C. Seixas, Rodolfo Staico, Luiz A. Mattos, Amanda G. M. R. Sousa, Robert Falotico, Judith Jaeger, Jeffrey J. Popma and Patrick W. Serruys Circulation 2001;103;192-195

Circulation is published by the American Heart Association. 7272 Greenville Avenue, Dallas, TX 72514

Copyright $@ 2001$ American Heart Association. All rights reserved. Print ISSN: 0009-7322. Online ISSN: $1524-4539$

The online version of this article, along with updated information and services, is located on the World Wide Web at: http://circ.ahajournals.org/cgi/content/full/103/2/192

Subscriptions: Information about subscribing to Circulation is online at http://circ.ahajournals.org/subsriptions/

Permissions: Permissions \& Rights Desk, Lippincott Williams \& Wilkins, 351 West Camden Street, Baltimore, MD 21202-2436. Phone 410-5280-4050. Fax: 410-528-8550. Email: journalpermissions@1ww.com

Reprints: Information about reprints can be found online at http://www.lww.com/static/html/reprints.html 


\title{
Lack of Neointimal Proliferation After Implantation of Sirolimus-Coated Stents in Human Coronary Arteries A Quantitative Coronary Angiography and Three-Dimensional Intravascular Ultrasound Study
}

\author{
J. Eduardo Sousa, MD, PhD; Marco A. Costa, MD, PhD; Alexandre Abizaid, MD, PhD; \\ Andrea S. Abizaid, MD; Fausto Feres, MD; Ibraim M.F. Pinto, MD; Ana C. Seixas, MD; \\ Rodolfo Staico, MD; Luiz A. Mattos, MD; Amanda G.M.R. Sousa, MD, PhD; Robert Falotico, PhD; \\ Judith Jaeger, BA; Jeffrey J. Popma, MD; Patrick W. Serruys, MD, PhD
}

Background - Restenosis remains an important limitation of interventional cardiology. Therefore, we aimed to determine the safety and efficacy of sirolimus (a cell-cycle inhibitor)-coated BX Velocity stents.

Methods and Results - Thirty patients with angina pectoris were electively treated with 2 different formulations of sirolimus-coated stents (slow release [SR], $\mathrm{n}=15$, and fast release [FR], $\mathrm{n}=15$ ). All stents were successfully delivered, and patients were discharged without clinical complications. Independent core laboratories analyzed angiographic and 3D volumetric intravascular ultrasound data (immediately after procedure and at 4-month follow-up). Eight-month clinical follow-up was obtained for all patients. There was minimal neointimal hyperplasia in both groups (11.0 $\pm 3.0 \%$ in the SR group and $10.4 \pm 3.0 \%$ in the FR group, $P=\mathrm{NS}$ ) by ultrasound and quantitative coronary angiography (in-stent late loss, $0.09 \pm 0.3 \mathrm{~mm}$ [SR] and $-0.02 \pm 0.3 \mathrm{~mm}$ [FR]; in-lesion late loss, $0.16 \pm 0.3 \mathrm{~mm}$ [SR] and $-0.1 \pm 0.3 \mathrm{~mm}[\mathrm{FR}]$ ). No in-stent or edge restenosis (diameter stenosis $250 \%$ ) was observed. No major clinical events (stent thrombosis, repeat revascularization, myocardial infarction, or death) had occurred by 8 months.

Conclusions-The implantation of sirolimus-coated BX Velocity stents is feasible and safe and elicits minimal neointimal proliferation. Additional placebo-controlled trials are required to confirm these promising results. (Circulation. 2001; 103:192-195.)

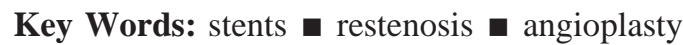

$\mathrm{R}$ estenosis remains a vexing problem of percutaneous intervention. The most promising approach to prevent restenosis has been the application of intracoronary radiation $^{1}$; however, some relevant side effects (edge restenosis and late thrombosis) have been reported.2,3 Numerous pharmacological approaches to reduce restenosis have failed, possibly due to insufficient local drug concentrations. ${ }^{4}$ Delivering medication directly to the site of vascular injury via polymeric-coated stents is a rational approach to achieve adequate local drug delivery. 5,6

Sirolimus (Rapamune), a natural macrocyclic lactone, is a potent immunosuppressive agent that was developed by Wyeth-Ayerst Laboratories and approved by the Food and Drug Administration for the prophylaxis of renal transplant rejection in $1999 .{ }^{7}$ Sirolimus binds to an intracellular receptor protein and elevates p27 levels, which leads to the inhibition of cyclin/cyclin-dependent kinase complexes and, ultimately, induces cell-cycle arrest in the late G1 phase. It inhibits the proliferation of both rat and human smooth muscle cells in vitro $^{8,9}$ and reduces intimal thickening in models of vascular injury. ${ }^{10-12}$ However, the effects of the local administration of sirolimus in a coated stent in humans have not been reported.

The aims of this pilot study were to assess (1) the feasibility and safety of implanting 2 different formulations of the sirolimus-coated BX Velocity stent in atherosclerotic human coronary arteries and (2) the impact of the stents on neointimal proliferation.

\section{Methods}

From December 1999 to February 2000, a single sirolimus-coated BX Velocity stent was successfully implanted in each of 30 consecutive patients with coronary artery disease. The stent is a

Received November 3, 2000; accepted December 4, 2000.

From the Institute Dante Pazzanese of Cardiology, São Paulo, Brazil (J.E.S., M.A.C., A.A., A.S.A., F.F., I.M.F.P., A.C.S., R.S., L.A.M., A.G.M.R.S.); Cordis, a Johnson \& Johnson Company, Warren, NJ (R.F., J.J.); Brigham and Women's Hospital, Boston, Mass (J.J.P.); and Thoraxcenter, Dijkzigt University Hospital, Rotterdam, the Netherlands (P.W.S.)

This article originally appeared Online on December 18, 2000. (Circulation. 2000;102:r54-r57.)

Correspondence to Prof J. Eduardo Sousa, MD, PhD, Director of the Institute Dante Pazzanese of Cardiology, Av Dr Dante Pazzanese, 500 - Ibirapuera, 04012180, São Paulo, Brazil. E-mail diretoriaidpc@uol.com.br

(c) 2001 American Heart Association, Inc.

Circulation is available at http://www.circulationaha.org 
laser-cut, 316L stainless steel, balloon-expandable stent that contains a fixed amount of sirolimus per unit of metal surface area (140 $\mu \mathrm{g}$ of sirolimus per $\mathrm{cm}^{2}$ ).

Sirolimus was blended in a mixture of nonerodable polymers that have been used clinically in bone cements, ocular devices, and a drug-releasing intrauterine device. ${ }^{13,14}$ Fifteen patients received a fast release (FR) formulation $(<15$-day drug release), and 15 received a slow release (SR) formulation ( $\geq 28$-day drug release).

\section{Procedure}

All stents were $18 \mathrm{~mm}$ long and 3.0 to $3.5 \mathrm{~mm}$ in diameter. After predilatation of the target lesion, stents were deployed with highpressure $(>14 \mathrm{~atm})$ postdilatation guided by intravascular ultrasound (IVUS). All patients received aspirin ( $325 \mathrm{mg} / \mathrm{d}$, indefinitely), which was started at least 12 hours before the procedure, and clopidogrel (300 mg immediately after stent implantation and $75 \mathrm{mg} / \mathrm{d}$ for 60 days). The protocol was approved by the Medical Ethics Committee of the Institute Dante Pazzanese of Cardiology, and informed consent was obtained from every patient.

\section{Quantitative Measurements}

Quantitative coronary angiography (QCA) and IVUS imaging were performed immediately after the procedure and at 4-month follow-up in all patients after a bolus infusion of intracoronary nitrates. IVUS images were acquired using motorized pull-back at a constant speed of $0.5 \mathrm{~mm} / \mathrm{s}$. Quantitative angiographic and volumetric IVUS analyses were performed by independent core laboratories (Brigham and Women's Hospital, Boston, Mass, and Cardialysis BV, Rotterdam, The Netherlands, respectively). ${ }^{15-17}$ Three segments were selected for volumetric IVUS analysis: the stented segment (18 $\mathrm{mm}$ long) and 2 edge segments that were axially $5 \mathrm{~mm}$ proximal and distal to the stent margins.

\section{Statistical Analysis}

Continuous variables are expressed as mean \pm SD. Comparisons between postintervention and follow-up measurements were performed with a 2-tailed paired $t$ test. Comparisons between groups were performed using an unpaired Student's $t$ test. $P<0.05$ was considered statistically significant.

\section{Results}

Twenty-six patients had stable angina and 4 patients had unstable angina. Their mean age was $57.9 \pm 10$ years (SR) and $55.1 \pm 7$ years (FR); $63 \%$ of the patients in each group were male. The incidence of prior myocardial infarction was $33.3 \%$ (SR) and $53.3 \%$ (FR), and $14 \%$ (FR) and $26 \%$ (SR) of the patients were diabetics. All stents were implanted successfully, and all patients were discharged without complications 24 hours after treatment. Creatine kinase and creatine kinase-MB levels, sampled at 6 and 18 hours after the procedure, were within the normal range in all patients.

Angiographic and volumetric IVUS data are presented in Tables 1 and 2 . No patient approached $\geq 50 \%$ vessel narrowing by QCA or IVUS, and only 3 patients had $>15 \%$ intimal hyperplasia (IH) by IVUS (Figure 1). In both the edge segments and in the stented segment, lumen loss detected by IVUS was minimal (Figure 2). All patients completed 4 months of angiographic and 8 months of clinical follow-up. There were no repeat revascularizations, stent thromboses, or major clinical events (cerebrovascular accident, myocardial infarction, or death).

\section{Discussion}

This is the first human experience with the implantation of sirolimus-coated BX Velocity stents. The absence of adverse

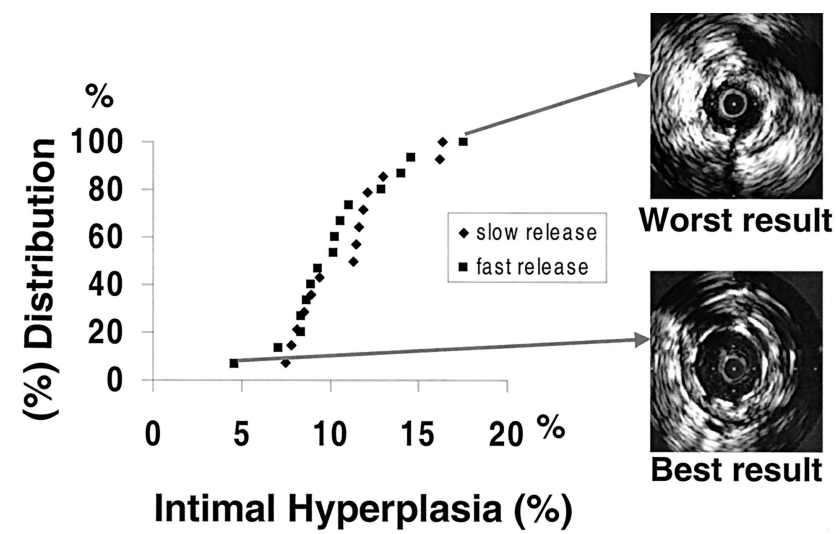

Figure 1. Left, Cumulative distribution curves of percent IH in SR and FR groups. Upper right panel shows follow-up IVUS cross-section with largest amount of IH (17.5\%), and lower right panel displays IVUS cross-section with lowest amount of $\mathrm{IH}$ (4.6\%). In both vessels, a FR stent was implanted (arrows).

events for up to 8 months of follow-up suggests that the implantation of this stent, which is coated with a potent cell-cycle inhibitor, is feasible and safe.

The amount of $\mathrm{IH}$ after the implantation of noncoated stents ranges from $19 \%$ to $48 \%$ of stent volume $3,18,19$ by IVUS, and late loss averages 0.8 to $0.9 \mathrm{~mm}$ by QCA. ${ }^{19}$ Even in nonrestenotic stents that are $\leq 15 \mathrm{~mm}$ long, an average $\mathrm{IH}$

TABLE 1. Offline Quantitative Coronary Analysis by Core Laboratory

\begin{tabular}{lcc}
\hline Parameters & SR Group $(\mathrm{n}=15)$ & FR Group $(\mathrm{n}=15)$ \\
\hline Before procedure & & \\
RD, mm & $2.98 \pm 0.4$ & $2.94 \pm 0.3$ \\
MLD, mm & $1.16 \pm 0.3$ & $0.93 \pm 0.4$ \\
DS, \% & $62 \pm 7$ & $68 \pm 14$ \\
Lesion length, mm & $12.9 \pm 1.97$ & $13.1 \pm 2.2$ \\
Lesion type B1, ${ }^{*} \%$ & 27 & 47 \\
Lesion type B2, $\%$ & 73 & 33 \\
After procedure & & \\
RD, mm & $3.1 \pm 0.4$ & $2.96 \pm 0.3$ \\
In-lesion MLD, mm & $2.74 \pm 0.4$ & $2.68 \pm 0.3$ \\
In-stent MLD, mm & $2.94 \pm 0.44$ & $2.84 \pm 0.3$ \\
In-lesion DS, \% & $11.44 \pm 5.5$ & $9.7 \pm 5.8$ \\
In-stent DS, \% & $5.09 \pm 6.72$ & $4.2 \pm 7.4$ \\
Follow-up & & \\
RD, mm & $2.99 \pm 0.4$ & $3.07 \pm 0.3$ \\
In-lesion MLD, mm & $2.6 \pm 0.5$ & $2.7 \pm 0.4$ \\
In-stent MLD, mm & $2.9 \pm 0.5$ & $2.93 \pm 0.3$ \\
In-lesion DS, \% & $14.5 \pm 9.1$ & $12.7 \pm 8.2$ \\
In-stent DS, \% & $5.04 \pm 6.7$ & $4.55 \pm 5.7$ \\
In-lesion late loss, mm & $0.16 \pm 0.3$ & $-0.02 \pm 0.3$ \\
In-stent late loss, mm & $0.09 \pm 0.3$ & $-1 \pm 0.3$ \\
\hline
\end{tabular}

Values are mean $\pm S D$. RD indicates reference diameter; MLD, minimum lumen diameter; and DS, diameter stenosis.

*According to AHA/ACC classification 
TABLE 2. Postprocedure and Follow-Up 3D IVUS Measurements by Core Laboratory

\begin{tabular}{|c|c|c|c|c|c|c|c|c|}
\hline & \multicolumn{3}{|c|}{ Lumen Volume, $\mathrm{mm}^{3}$} & \multicolumn{3}{|c|}{ Stent Volume, $\mathrm{mm}^{3}$} & \multicolumn{2}{|c|}{ Neointimal Hyperplasia } \\
\hline & Post & FUP & $P$ & Post & FUP & $P$ & Volume, $\mathrm{mm}^{3}$ & Percent \\
\hline Total & $141.6 \pm 35$ & $127.8 \pm 36$ & $<0.01$ & $141.6 \pm 35$ & $142.8 \pm 39$ & NS & $15.0 \pm 5$ & $10.7 \pm 3.0$ \\
\hline SR group & $152.2 \pm 40$ & $137.6 \pm 40$ & $<0.01$ & $152.2 \pm 40$ & $154.4 \pm 44$ & NS & $16.8 \pm 6$ & $11.0 \pm 3.0$ \\
\hline FR group & $131.3 \pm 31$ & $118.7 \pm 30$ & $<0.01$ & $131.3 \pm 31$ & $132.0 \pm 31$ & NS & $13.3 \pm 4$ & $10.4 \pm 3.0$ \\
\hline$P$ & NS & NS & & NS & NS & & 0.07 & NS \\
\hline
\end{tabular}

of $19.7 \%$ has been observed by IVUS. ${ }^{18}$ Although differences in population and stent design limit scientific comparison with other reports, it is worth noting that the amount of IH detected in the present study (10.7\%; essentially zero late loss by QCA) is much lower than previously reported. This is likely due to the cytostatic effect of sirolimus. ${ }^{10-12,20}$

Using the same IVUS methodology, the amount of in-stent IH with radioactive stent implantation varied from $7.4 \%$ (6 to $12 \mu \mathrm{Ci}$ radioactive stent) to $16.7 \%(0.75$ to $1.5 \mu \mathrm{Ci}){ }^{17}$ However, neither edge restenosis nor stent thrombosis, both of which have been reported after radiation, ${ }^{2,3}$ were observed after the implantation of sirolimus-coated stents (Figure 2).

As a result of their permanent scaffolding action, stents have become an attractive platform for delivering medications locally. ${ }^{5,21}$ Although some polymers have been associated with a marked inflammatory reaction, ${ }^{22}$ these findings were not observed with the polymers used in the present investigation or in other clinical situations. ${ }^{13,14}$ In the present study, similar favorable results were observed with both the FR and SR formulations of the sirolimus-coated stent. Whether one sirolimus coating matrix is superior to the other (SR versus FR) requires further investigation.

\section{Limitations}

The study comprises a registry of only 30 patients with 4 months of QCA and 3D IVUS data and 8 months of clinical data. However, considering the absence of late loss by QCA and the virtual absence of IH observed in the present study by 3D IVUS and the well-documented degree of late loss with uncoated stents, these early results are promising. Twelvemonth angiographic and IVUS follow-up will be performed in all patients to assess whether this effect is sustained.

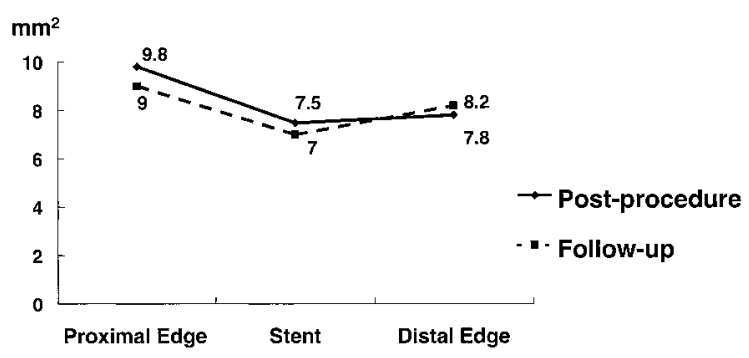

Figure 2. Postprocedure and follow-up mean lumen areas within stent and at $5-\mathrm{mm}$ edge segments $(n=30)$, as assessed by 3D IVUS.

\section{Conclusion}

Sirolimus-coated BX Velocity stents seem to be safe and effective in preventing neointimal formation at 4 months after stent implantation in de novo lesions. These seminal findings warrant further confirmation by large, placebo-controlled, multicenter trials.

\section{Acknowledgments}

This study was sponsored by Cordis, a Johnson \& Johnson Company. We thank Dr Brian Firth for his careful review of the manuscript.

\section{References}

1. Teirstein PS, Massullo V, Jani S, et al. Catheter-based radiotherapy to inhibit restenosis after coronary stenting. $N$ Engl J Med. 1997;336: 1697-1703.

2. Albiero R, Nishida T, Adamian M, et al. Edge restenosis after implantation of high activity (32)P radioactive $\beta$-emitting stents. Circulation. 2000;101:2454-2457.

3. Costa MA, Sabate M, van der Giessen WJ, et al. Late coronary occlusion after intracoronary brachytherapy. Circulation. 1999;100:789-792.

4. Lafont A, Faxon D. Why do animal models of post-angioplasty restenosis sometimes poorly predict the outcome of clinical trials? Cardiovasc Res. 1998;39:50-59.

5. Lincoff AM, Topol EJ, Ellis SG. Local drug delivery for the prevention of restenosis: fact, fancy, and future. Circulation. 1994;90:2070-2084.

6. Topol EJ, Serruys PW. Frontiers in interventional cardiology. Circulation. 1998;98:1802-1820.

7. Groth CG, Backman L, Morales JM, et al. Sirolimus (rapamycin)-based therapy in human renal transplantation: similar efficacy and different toxicity compared with cyclosporine: Sirolimus European Renal Transplant Study Group. Transplantation. 1999;67:1036-1042.

8. Marx SO, Jayaraman T, Go LO, et al. Rapamycin-FKBP inhibits cell cycle regulators of proliferation in vascular smooth muscle cells. Circ Res. 1995;76:412-417.

9. Poon M, Marx SO, Gallo R, et al. Rapamycin inhibits vascular smooth muscle cell migration. J Clin Invest. 1996;98:2277-2283.

10. Gregory CR, Huang X, Pratt RE, et al. Treatment with rapamycin and mycophenolic acid reduces arterial intimal thickening produced by mechanical injury and allows endothelial replacement. Transplantation. 1995;59:655-661.

11. Burke SE, Lubbers NL, Chen YW, et al. Neointimal formation after balloon-induced vascular injury in Yucatan minipigs is reduced by oral rapamycin. J Cardiovasc Pharmacol. 1999;33:829-835.

12. Gallo R, Padurean A, Jayaraman T, et al. Inhibition of intimal thickening after balloon angioplasty in porcine coronary arteries by targeting regulators of the cell cycle. Circulation. 1999;99:2164-2170.

13. Kindt-Larsen T, Smith D, Jensen J. Innovations in acrylic bone cement and application equipment. J Appl Biomater. 1995;6:75-83.

14. Revell P, Braden M, Freeman M. Review of biological response to a novel bone cement containing poly(ethyl methacrylate) and n-butyl methacrylate. Biomaterials. 1998;19:1579-1586.

15. Lansky AJ, Popma JJ, Cutlip D, et al. Comparative analysis of early and late angiographic outcomes using two quantitative algorithms in the 
Balloon versus Optimal Atherectomy Trial (BOAT). Am J Cardiol. 1999; 83:1611-1616.

16. Costa MA, Sabatt M, Kay IP, et al. Three-dimensional intravascular ultrasonic volumetric quantification of stent recoil and neointimal formation of two new generation tubular stents. Am J Cardiol. 2000;85:135-139.

17. Kay IP, Sabate M, Costa MA, et al. Positive geometric vascular remodeling is seen after catheter-based radiation followed by conventional stent implantation but not after radioactive stent implantation. Circulation. 2000;102:1434-1439.

18. Dussaillant GR, Mintz GS, Pichard AD, et al. Small stent size and intimal hyperplasia contribute to restenosis: a volumetric intravascular ultrasound analysis. J Am Coll Cardiol. 1995;26:720-724.
19. The ERASER investigators. Acute platelet inhibition with abciximab does not reduce in-stent restenosis (ERASER study). Circulation. 1999; 100:799-806.

20. Poston RS, Billingham M, Hoyt EG, et al. Rapamycin reverses chronic graft vascular disease in a novel cardiac allograft model. Circulation. 1999;100:67-74.

21. Camenzind E, Kutryk M, Serruys P. Use of locally delivered conventional drug therapies. Semin Interv Cardiol. 1996;1:67-76.

22. van der Giessen WJ, Lincoff AM, Schwartz RS, et al. Marked inflammatory sequelae to implantation of biodegradable and nonbiodegradable polymers in porcine coronary arteries. Circulation. 1996;94:16901697. 